\title{
A utilização do fundo oral do Proxecto Interuniversitario "Nomes e Voces". Estudo de caso: causas e sujeitos da perseguição política e repressão na guerra e a ditadura de Franco na Galiza (1936-...)*
}

\author{
Judith Carbajo Vázquez** \\ Lourenzo Fernández Prieto***
}

Perguntas de partida

Parece que os debates que surgiram, no passado, sobre a natureza do franquismo e o grande crescimento dos estudos, de qualidade diversa, sob a polémica na Espanha da mal chamada "memória histórica" fizeram com que fosse dada preferência não apenas à análise das repressões, mas também ao estudo do fenómeno da violência e da perseguição política, em sentindo amplo, desde a história comparada e interdisciplinar, até em âmbitos mais restritos, como a exploração dos sujeitos repressores. Desse quadro, partem as

* Tradução de André Taboada Casteleiro.

** Investigadora no Departamento de Historia Contemporánea e de América na Universidade de Santiago de Compostela.

*** Catedrático de Historia Contemporánea no Departamento de Historia Contemporánea e de América na Universidade de Santiago de Compostela e investigador principal do Proxecto Interuniversitario "Nomes e Voces". 
principais perguntas que tencionamos examinar neste estudo: quem e quantos eram os repressores, quais as causas e as motivações das suas atuações? Este trabalho é realizado desde a história, isto é, com um objetivo científico, de conhecimento. Não visamos virar juízes, mas fazer uma análise como historiadores: investigar os perfis socioculturais, políticos, laborais dos repressores, bem como as suas redes, estruturas e ligações com outros grupos (participantes ativos-promotores, passivos, etc.).

Por que um exame das causas e dos sujeitos repressores? Porque o coletivo dos repressores permaneceu demasiado oculto pelo tempo e protegido por fatores políticos e jurídicos, alguns de relevância internacional e que chegam até à atualidade. Da metodologia histórica, propomos a análise das causas e dos sujeitos da perseguição política, assim como da repressão, das motivações, das estruturas de poder local e civil, que nos ajudem a compreender, em última instância, a conformação do regime franquista desde a sua consolidação, ao mesmo tempo em que vence a guerra e, depois disso, a sua conquista violenta do poder. Nosso foco é o território da Galiza. ${ }^{1} \mathrm{Em}$ uma região como Galiza, que ficou rapidamente sob o domínio das forças revoltosas, a instauração do novo regime foi fundamentada na implementação das práticas repressivas. Será da perspetiva local que poderemos vir a analisar as várias lógicas repressivas com vista a melhor compreendermos nem só como se foi configurando a estrutura do novo regime, mas também como se formaram as tramas civis tão importantes para a definição da própria ditadura. Ela foi construída com base em um sistema de repressores, delações e acusações que configuram o seu braço civil. Tal sistema fez com que grande parte da sociedade viesse a ficar envolvida nele, uns enquanto delatores, outros enquanto

1 Galiza, com origem num dos antigos reinos hispanos - que dá origem a Portugal - é atualmente uma comunidade autónoma do Estado espanhol, com rango constitucional de nacionalidade histórica, pelos seus precedentes autonómicos na II ${ }^{a}$ República. Situada no noroeste da Península Ibérica, sua capital é Santiago de Compostela e as demais cidades são Vigo, A Coruña, Ourense, Pontevedra, Lugo e Ferrol. Com uma costa vasta de $1500 \mathrm{~km}$ dominada por grandes "rías", faz divisa ao oeste com o Oceano Atlântico, ao norte com o mar Cantábrico, ao sul com Portugal e ao leste com Asturias e Castela-León. Nos seus $29.500 \mathrm{~km}^{2}$ vivem atualmente 2,8 milhões de habitantes, e a emigração desde o século XIX levou pelo mundo um número equivalente de galegos. Sua característica socioeconómica mais marcante define-se por este olhar para o mar: importante em pescas (segunda frota europeia), produção de frutos do mar e construção naval; tem outro olhar para dentro, baseado na pequena exploração agrária familiar (pecuária, agricultura e cantaria) que enfatizou o seu forte caráter rural até há pouco. Essas marcas socioeconómicas encontram-se já na década de 1930, contexto em que este trabalho se situa. Depois evoluiu também uma orientação florestal, energética e têxtil (Inditex-Zara). A sua língua é o galego, similar e de comum origem com o português. 
famílias destes, e uns outros enquanto gente que ocupou os postos deixados pelos assassinados ou expurgados.

Nesse processo de análise, partimos do estudo pormenorizado das fontes secundárias e do exame de fontes primárias. Dentre essas, as fontes orais devêm essenciais enquanto ponto de partida para a nossa análise, apesar dos seus condicionantes e subjetividades. Para isso, investigamos, por uma parte, o que as vítimas dizem relativamente aos seus carrascos e à repressão a partir do exame de todo o fundo sonoro do Proxecto Interuniversitario "Nomes e Voces" de vítimas da repressão franquista; e, por seu turno, o que os carrascos afirmam a respeito das vítimas e os processos de repressão, através das fontes orais do fundo de Historia Oral de Galicia (HISTORGA). ${ }^{2}$ Já a seguir e numa segunda fase da nossa investigação, trabalharemos em profundidade, as fontes documentais surgidas das causas militares do Arquivo Militar de Ferrol, entre outras.

Uma das nossas hipóteses de partida é que pode ter existido certo envolvimento da sociedade local, com diversos graus de atividade, nas violências e repressões franquistas. Esse envolvimento pode ter ajudado ao objetivo final de paralisação da resistência, a mobilizar recursos para a "frente" e, finalmente, a garantir a imposição gradual de uma nova ordem política e social, de um "Estado Novo", através da eliminação de qualquer perigo real ou potencial. O exame e a análise dos graus de envolvimento, dos tipos de violências e dos seus sujeitos repressores ajudar-nos-á a melhor identificar as suas identidades, estruturas e comportamentos. Eis o ponto de partida do nosso estudo e é através dele que tentaremos aproximar-nos do objetivo central,

2 Em 2006, as universidades galegas (Santiago, Vigo e A Coruña) iniciaram a pesquisa sistemática da persecução franquista em Galiza entre 1936 e 1939, no Proxecto Interuniversitario "Nomes e Voces” com o impulso da Consellería de Cultura da Xunta de Galicia e com o assessoramento externo de Conxita Mir e Ángela Cenarro. O projeto aproveitou a trajetória investigadora desenvolvida desde a década de 1980 pela equipa de Julián Casanova em Aragón ou em Catalunha por J. Ma Solé i Sabaté, J. Villaroya e outros. $\mathrm{Na}$ pesquisa, realizaram-se mais de 500 entrevistas com vítimas e familiares diretos. Outros projetos associados a este: A socialización na guerra contra a República e os apoios da ditadura franquista (2009/ PX303. Xunta de Galicia); Políticas agrarias en un contexto autoritario, de la autarquía a la revolución verde (1940-1980) (HAR2010-18668. Ministerio de Ciencia y Tecnología) e La fuente oral como base para el estudio de la represión. El caso de la represión colonial francesa en Túnez y franquista en Galicia (AECID-Ministerio de Asuntos Exteriores). Para uma apresentação detalhada do Proxecto Interuniversitario "Nomes e Voces", ver Fernández (2008). O fundo HISTORGA (Historia Oral de Galicia) foi construído no Departamento de Historia Contemporánea da USC desde finais dos anos 1980 por Marc Wouters, Isaura Varela e Xurxo Pantaleón. Na atualidade, conformam um conjunto que já supera 1600 entrevistas, sobre aspetos centrais da história recente de Galiza, entre os quais se salientam a guerra civil e a emigração. 
isto é, a partir do conhecimento da história positiva (das violências e repressões franquistas), investigar o porquê, as razões das perseguições e do massacre (políticas/conquista do poder, militares, sociais, religiosas) de modo a melhor compreender a forma como atuavam os sujeitos repressores bem como as suas motivações, procedimentos e justificações. Apesar de não haver dúvida, hoje em dia, sobre a identificação desses sujeitos repressores, através do referido tratamento visamos investigar, como um dos objetivos centrais, as motivações ou como é que a perseguição política e a repressão da guerra civil e a ditadura franquista se produziram, em uma área específica, na qual não houve "frente" e que ficou prontamente sob o domínio dos revoltosos. Pretende-se, com isso, analisar o significado do conjunto das práticas genocidas e dos sujeitos da perseguição política e a repressão em termos interpretativos; provar que para os vencidos não houve paz, e, com tudo isso, revelar, matizar ou qualificar aquilo que P. Preston (2011) considera como a fraqueza da camada civilizada que cobre uma sociedade. ${ }^{4}$

É o facto de a Galiza ter ficado imediatamente sob controlo revoltoso que explica muitos dos fenómenos repressivos que se seguiram, sobretudo no nível local - uma violência encenada na Galiza apenas na retaguarda - já que não havia frente de guerra - e que caracterizou a estruturação de um novo poder político assente na repressão ao "inimigo" (dentro da criação de identidades binárias) e na institucionalização da repressão. Sustentamos que, através do amplo campo conceptual e metodológico desenvolvido para o estudo das violências e repressões e com a apreensão dos resultados das investigações para o contexto galego, poderemos bem tirar algumas conclusões relativamente à identidade das vítimas e dos carrascos e, mesmo, sobre a funcionalidade da estrutura repressiva. Tentaremos investigar e analisar a partir deles as origens, debruçarmo-nos sobre o desenvolvimento das tramas que o regime veio a impulsionar através das várias repressões que atuaram neste território e, daí, compreenderemos a estrutura, os fundamentos e as caraterísticas de uma ditadura que depois de instaurada, sobreviveu por décadas.

3 O golpe militar começou em 18 de julho e no dia 31 não havia nenhuma frente de guerra aberta na Galiza. Em poucos dias, os militares golpistas submeteram as resistências cívicas e armadas dos defensores da democracia republicana.

4 O ensaio de Preston (2011) revela a fragilidade da camada civilizada, sobrepondo-se a uma sociedade. Ele incomoda ao defender que "um Holocausto é o massacre de um povo. E, eu diria que o sofrimento e a dor do povo espanhol justificam esse título" (Constenla, 2001). 


\section{Uma metodologia nova para umas fontes conhecidas}

Os estudos sobre a violência política e a repressão durante a guerra civil e a ditadura continuam a crescer, não apenas numericamente, mas também - e é isso que visamos refletir na nossa investigação - quanto ao aprimoramento de novas fontes e à utilização de instrumentos melhorados de análise e de conceitos mais ajustados que permitam a extrapolação de categorias de análise utilizados em outros contextos internacionais para o caso espanhol e a verificação do seu grau de efetividade. É por tudo isso que visamos colocar a nossa investigação dentro de uma nova aproximação das fontes orais e documentais que já têm sido trabalhadas para o estudo das vítimas e que, graças a uma metodologia ad hoc, pode nos dar uma ideia mais ajustada da estrutura repressiva. Pretendemos, também, avaliar quais os conceitos mais adequados ao nosso processo de estudo.

Nesse sentido, preferimos não utilizar para o nosso estudo o termo “repressão" sendo, em qualquer caso, empregue apenas no plural para assim melhor refletir o caráter poliédrico da repressão na guerra e na ditadura franquista. Para isso acompanharemos, de uma maneira geral, a proposta metodológica de sistematização das "modalidades repressivas" de Julio Prada (2003) com base em quatro categorias (repressão paralegal, institucionalizada, social e psicológica) que nos ajudará na hora de identificar as "lógicas” da violência. Para além disso, concordamos com J. Rodrigo (2009, p. 18) quanto a que o conceito de repressão "pressupõe uma resposta perante um facto precedente, sem abarcar a caraterização preventiva que, em muitos casos, a violência teve na retaguarda". Achamos, assim, mais pertinente o conceito de "violências políticas" que, como categoria de análise histórica, permite-nos examinar tempos/contexto de desenvolvimento da violência, estabelecer tipologias ou, ainda, explorar o terreno da subjetividade e da percepção da violência política e simbólica desenvolvida pelos aparelhos do poder franquista. No que respeita à centralidade da violência no interior das relações sociais das retaguardas, para o caso galego, torna-se fundamental a utilização das categorias de "retaguarda" e de "cultura de guerra" e a colocação delas em relação com o complicado campo do "consenso". A violência torna-se o eixo central da guerra e do pós-guerra, ao ponto de chegar a definir mesmo ao inimigo-amigo fazendo com que as fraturas sociais herdadas de décadas anteriores deviessem mais profundas e se afiançassem mitos e representações. 
Partindo da nossa hipótese inicial na hora de investigar e analisar o processo de conformação de um regime como o franquista - obre um sistema de violência, repressões e uma emaranhada estrutura de repressores, delatores e colaboradores civis - torna-se imprescindível adotar uma perspetiva de análise local, tal e como viemos apontando. A perspetiva metodológica micro resulta-nos funcional, não apenas desde a metodologia histórica, mas também pela necessidade de estudar sociedades rurais como a galega. Por conseguinte, um contexto tão ruralizado, como o galego da altura, ajuda-nos a melhor compreender as várias repressões desenvolvidas pelos revoltosos. É desse nível de análise que avaliaremos as maquinações do poder local, os seus antecedentes, as suas recomposiçôes no contexto bélico e pós-bélico, bem como a identificação das conspirações civis (a depender sempre do rendimento que nos oferecerem as fontes). Ficarão sempre abertas as possibilidades de readaptações metodológicas quer relativamente às fontes documentais, quer às orais.

Com vista a uma correta caracterização e categorização das fontes documentais, e devido, precisamente, à carência destas para o estudo dos sujeitos repressores, aquelas que trabalhamos foram utilizadas, em parte, para o estudo da repressão franquista. No nosso estudo, perspetiva-se uma análise diferente, e que tencionamos prender, ao mesmo tempo, com outros elementos que nos ajudarão na hora de explorar outras hipóteses de análise dos sujeitos repressores e processos, como é o caso das fontes orais. Os fundos orais que analisamos são os do Proxecto Interuniversitario "Nomes e Voces" (www.nomesevoces.net) e os do fundo de Historia Oral de Galicia (HISTORGA) (http://www.usc.es/gl/departamentos). O fundo que acolhe o referido projeto foi concebido para o estudo da repressão e as suas vítimas na Galiza e conta com mais de 500 entrevistas digitalizadas e indexadas. Para o nosso trabalho, fizemos uma exaustiva consulta de todos os índices de indexações e selecionamos assim aqueles aspetos da indexação do fundo que nos pudessem ajudar a encontrar os elementos relacionados. Para buscarmos elementos sobre causas/motivaçóes/sujeitos repressores, por exemplo, serviram as categorias: $<$ Repressão-repressores $>$, $<$ Falange e direitas antirregime $>$ ou $<$ Igreja $>$. Essas categorias sequenciamo-las em vários momentos (antes do golpe de Estado, na guerra e no pós-guerra). Depois da localização e seleção, resultaram mais de 30 entrevistas de vítimas das repressões que foram analisadas integralmente através de escuta (Anexo 1).

Perante um trabalho tão extenso tivemos que desenhar uma metodologia específica de análise de entrevistas com base em dois modelos de quadros 
de exploração: um voltado para o exame das atuações repressivas ("contexto", "membros e descrição", "atuações/vítimas, local", "motivações"); e um outro, a partir do parâmetro de "membros", de forma a analisar os sujeitos repressores, o que inclui mesmo a exploração de elementos como "indivíduo/grupo", "visibilização" ( simbolismo), "relação com outros grupos" e "motivações”. Foi graças a essa metodologia que pudemos chegar a reconhecer os repressores enquanto sujeitos, bem como algumas das suas motivações: desde a análise pormenorizada das suas descrições gerais às das suas atuações. Para completar a exploração dos sujeitos repressores analisamos os fundos de HISTORGA com base em uma filtragem de duas das suas categorias de indexação < Repressão-repressores $>$ e $<$ Falange e direitas antirregime $>$, da qual obtivemos vinte entrevistas de protagonistas ativos/passivos das repressões na Galiza, sendo que a maior parte destes fundos refletem o ponto de vista falangista. Aplicamos ainda uma metodologia já desenvolvida para o fundo do Proxecto Interuniversitario "Nomes e Voces" ajustando, no entanto, o segundo quadro de trabalho, ao serem sete as entrevistas transcritas. Através da análise desses fundos pudemos examinar as fontes da perspetiva das vítimas e dos repressores, complementando-se ambas, sem esquecermos, contudo, o seu grau de subjetividade e um contraste/complemento com as fontes documentais. É por essa razão que completamos o tratamento com fontes alternativas, secundárias (a história geral do conflito e repressões) e primárias orais (ponto de vista dos falangistas) e documentais, como causas militares e juízos, o que nos permitiu aprofundar nos termos sociais o coletivo que é nosso objeto de estudo.

Relativamente à documentação judiciário-militar, partimos de considerá-las fundamentais nesta investigação. Elas foram analisadas não para o estudo das vítimas, como tinham sido tratadas até ao momento (aproximação quantitativa à atividade desenvolvida, tipologia das condenações, evolução de acórdãos, perfil sociopolítico dos processados), mas focando a sua análise na atitude dos envolvidos na repressão: quem inicia as causas, quem é que realiza os acórdãos, as alegações, quais os grupos que apresentam testemunhas, etc. Como acima assinalamos, essa nova aproximação das fontes, pelas consultas já efetuadas, fornece-nos evidências que nos resultarão muito operacionais quando enfrentados com posteriores fases da investigação. Portanto, o que estamos fazendo é explorar as possibilidades de análise dos sujeitos repressores através daquelas fontes que até ao momento tinham sido utilizadas metodologicamente para o estudo das vítimas da repressão e valorizar o grau de alcance das suas possibilidades para uma investigação como a propositada. 


\section{A violência política: os sujeitos repressores: quem e com quem? A urdidura dos sujeitos que participaram na estrutura repressiva através dos "outros nomes" das "mesmas vozes"}

Conhecidas as modalidades repressivas que adota a violência política, os procedimentos, vítimas, etc., resta-nos avaliarmos uma peça fundamental que continua a não ser tratada pela historiografia, com, pelo menos, a mesma qualificação de objeto histórico: os sujeitos repressores. Só nos últimos tempos é que tem vindo a surgir uma nova abordagem, não sendo desde a história, que tem publicado listagens de pessoas que estiveram vinculadas ou filiadas a grupos como a Falange Española (FE), que fizeram parte das Guardias Cívicas ou qualquer outro tipo de milícias ou que pertenciam ao corpo da Guardia Civil, entre outras; tentativa errada, achamos, de aproximação dos carrascos da repressão. Para além dos "nomes", o que por aqui tencionamos é aproximarmo-nos dos "sujeitos" das repressóes na Galiza. Em um primeiro momento dessa investigação, através das fontes orais e, como explicávamos, em posteriores etapas, continuaremos a investigar outras fontes que nos permitam contrastar e completar a urdidura dos sujeitos que participaram da estrutura repressiva. No processo que por aqui começamos, não nos recusamos a incluir também os "nomes" que as fontes nos fornecem, em alguns casos mesmo não são novos, em outro, sim. Contudo, serão tratados enquanto elementos nos quais continuaremos a colocar a atenção em posteriores fontes que analisemos, como linhas que nos levam para os caminhos das lógicas repressivas e dos seus sujeitos e contextos, portanto, como sujeitos históricos.

Desde o início do projeto deparamos com algumas dificuldades para a sua abordagem, desde a perspetiva que nos concerne, isto é desde a história: a dificuldade na hora de encontrarmos fontes e, no caso em que contávamos com elas e dispúnhamos de um acesso adequado às mesmas, as dificuldades que se seguiam quanto à análise dos sujeitos repressores, pois a quase totalidade delas tinha o foco colocado nas vítimas. No caso das fontes orais, tanto nas entrevistas dos sujeitos repressores quanto naquelas das vítimas, tivemos que levar em conta a adaptação da experiência vivida no passado aos valores atuais e à história e as transformações e seleções operadas pela memória. 
Achamos que a forma mais eficaz de nos aproximar do nosso objeto de estudo e poder assim obter resultados para a nossa análise tinha de acompanhar a estrutura das modalidades repressivas. É por isso que dividimos a exposição dos resultados da análise entre a repressão paralegal e a institucionalizada. Sabemos, no entanto, que se trata de duas expressões da mesma violência, sendo que frequentemente se torna difícil diferenciar aonde é que chega uma e outra, misturando-se e confundindo-se atuações e sujeitos. Mesmo assim, não renunciamos a tratá-las de uma maneira individual só com fins expositivos/didáticos. Neste trabalho, serão expostos os primeiros resultados que dizem respeito aos sujeitos repressores no âmbito da repressão conhecida como paralegal.

\section{Sujeitos repressores na repressão paralegal}

Comecemos por expor a funesta cadeia de ordens e instruções desde a qual eram orientados os episódios da repressão paralegal. Torna-se fácil compreender que esta era, frequentemente, ultrapassada e alterada pela própria modalidade da violência repressiva, principalmente além do nível nacional, quando a repressão desce mesmo para o microcosmos local.

É conhecido que, nos primeiros cenários que se seguiram ao golpe, são as "milícias patrióticas" que são armadas e que passam a colaborar com o comando militar nas tarefas de desarticulação da localizada resistência galega; são, por fim, as encarregadas de manterem a ordem, de efetivarem as "pacificações". Dentre essas milícias, os mais destacados serão membros da Falange, das JAP e Requetés, ${ }^{5}$ sob a direção dos militares e, em contextos locais, também da Guardia Civil.

Contudo, não devemos negligenciar o facto de o exército ter continuado a ser o principal responsável por essas iniciativas e pelo clima de violência que envolve toda a retaguarda. Os militares controlavam todos os mecanismos de poder, detinham as atribuições em matéria de ordem pública e submetiam toda a justiça civil à militar, embora tivessem que dispor da polícia, a Guardia

5 Grupos paramilitares atuantes como unidades de controlo da retaguarda, vinculados a partidos ou a organizações político-sindicais: do partido fascista espanhol (Falange Espanhola); das Juventudes de Acción Popular (JAP) - o mais importante partido da direita católica - e dos carlistas-católicos-tradicionalistas, cujas unidades paramilitares denominavam-se Requetés. 
Civil, Guardias de Asalto, etc. para que isso fosse concretizado. ${ }^{6}$ Nesse tipo de atuações represssivas temos que diferenciar o primeiro período (desde o golpe de julho de 1936), muito violento, de outro, a partir de dezembro de 1936, quando esses grupos ficam submetidos ao código de justiça militar. ${ }^{7}$ Contudo, as diretrizes são sempre fixadas pelo mais alto nível do poder sublevado. O fato de o único poder na retaguarda ter ficado nas mãos da nova "iure", isto é, em mãos militares, não pode ser negligenciado, embora a sua "praxe" fosse desenvolvida e executada, ao nível provincial, pelas autoridades militares e, no nível local, pela Guardia Civil ou pelo delegado de Ordem Pública, e induzida, em muitos casos, pelos caciques locais, como veremos mais à frente. É nesse ponto que poderíamos perguntar-nos se, com efeito, as autoridades militares dispunham de mecanismos adequados ao controlo efetivo de toda a estrutura repressiva. Sabemos que com o "bando de guerra", os militares detinham toda a autoridade no que diz respeito à ordem pública, sendo, por essa razão, que eles próprios entregaram nos primeiros dias as armas a falangistas e às milícias, e mesmo os encorajaram a colaborarem naqueles pontos de resistência. ${ }^{8}$ Depois dos primeiros dias, ao longo do verão e outono de 1936, é que ocorre o maior número de assassinatos no âmbito das repressões tipificadas como paralegais, protagonizadas pelas milícias e, dentro de elas, a Falange ocupa um lugar proeminente. Contudo, no que ao modus operandi da repressão paralegal diz respeito, essa sinistra cadeia de comando também podia vir a ser alterada, surgindo como executores diretos cargos militares,

6 Assim, partilhamos a tese de que os militares teriam sido os responsáveis por todos esses assassinatos ocorridos no âmbito da repressão paralegal cometidos pelas milícias, como uma espécie de polícia política dos militares, um instrumento político da repressão, longe de ser um fenómeno fora de controlo daqueles e alheio às autoridades civis e militares. Essa é a tese mais assumida para o caso da repressão em todo o território espanhol (cf. Aróstegui, 1994; Brenan, 1985; Casanova, 1992, 2002; Jackson, 1995, 2002; Payne, 2005, 2008; Thomas, 1995; Tusell, 2001, 2005, 2007). Para o caso galego surgem algumas discrepâncias quanto à titularidade da responsabilidade última; autores como J. Fernández (2000, p. 93) sustentam que no caso dos paseos a causa é atribuída à "inveja, à impotência mental, ao desapreço..." exculpando os militares da participação direta nos mesmos, embora o autor reconheça, ao mesmo tempo, que essas atuações realizavam-se sob autoridade militar.

7 Aqui deparamos com a famosa tese de que a fortíssima repressão a nível nacional conhece um ponto de inflexão logo a seguir à batalha de Madri e que será a partir do inverno de 1936 e na sequência do prolongar da guerra que a dinâmica repressiva se tornará menos indiscriminada e massiva.

8 O "bando de guerra" é um edito ou mandato publicado pela autoridade militar declarando a toma do poder pela declaração do estado de guerra e pretensamente amparado na própria legislação republicana. 
guardas civis, ${ }^{9}$ guardas de assalto e segurança, cívicos, ${ }^{10}$ polícias e, mesmo, párocos. ${ }^{11}$

Dentro dos falangistas temos que diferenciar, para o estudo em questão, entre os falangistas camisas viejas e as rápidas incorporações. ${ }^{12}$ Foram principalmente os camisas viejas que receberam muitas das instruções militares orientadas para a repressão. Esses grupos conheciam bem uma retaguarda para a qual contribuíram nem só a "limpar" mas também a construir e controlar, graças aos seus serviços em postos que ocuparão na administração, revelando essa "adaptação" aos novos equilíbrios do poder local após o golpe. Consoante o relato de um antigo militante da Falange Española Tradicionalista e das Juntas de Ofensiva Nacional Sindicalista (FET e JONS, respetivamente) de Ourense, entrar na Falange acabava sendo "atraente". ${ }^{13}$

9 Embora, em alguns casos, era a própria Guardia Civil a se desempenhar como protagonista dos paseos, um dos sujeitos mais reconhecidos é o famoso guarda civil, o "Rabioso" (Francisco González Rodríguez, falangista e tenente da Guardia Civil em Vigo), cuja alcunha provém de ter atado ao seu cavalo uma corda com a qual arrastava a vítima pelas ruas. É ao referido guarda civil que é atribuído o primeiro paseado em Vigo, um transportador de peixe, antigo sindicalista e membro da CNT (José Manuel Taboada Martínez, registado morto em Vigo por causa de hemorragia por ferimentos de projétil. Local de aparecimento do cadáver: via pública -Vigo. Fundo Proxecto Interuniversitario "Nomes e Voces"), o qual, ferido na ocorrência do golpe em Vigo, foi na sua procura ao sanatório do Dr. Troncoso e foi assassinado em Balaídos (bairro da cidade de Vigo).

10 Foi Víctor Lis Quibén (Médico, URD, deputado RE, FE), organizador da Guardia Cívica em Pontevedra e responsável por inúmeras execuções extrajudiciárias, que se revelou entre os mais sangrentos repressores. Consoante o relato do filho de Amancio Caamaño Cimadevila (médico, executado), é sob a ordem de Lis Quibén que são fuziladas seis pessoas, sendo ainda o responsável pela execução de assassinatos e ordens de paseos desde o Lazareto (Ilha de S. Simón, Vigo) (Fundo 2074 A. C. C. Proxecto Interuniversitario "Nomes e Voces").

11 Entre muitos, por exemplo, uma testemunha situa o pároco de Bouzas (Vigo), padre Comesaña, relacionado com as atuações diretas dos falangistas dos arredores: "o padre Comesaña levava pistola, mesmo em missa, por baixo da sotaina” (Fundo 2037 C. N. M. Proxecto Interuniversitario “Nomes e Voces”).

12 Lembremos que os filiados à Falange nas províncias galegas não eram, em termos comparativos, um número importante, mesmo na província de Ourense, que era a que maior índice registava desde a fundação do partido. Por sua vez, quanto às novas incorporações "para salvar a sua própria pele", existem muitas fontes que registam uma enxurrada de novos ingressos de jovens falangistas, sobretudo logo a seguir ao golpe, por motivações/interesses muito diversos. Mas, para além das operações de "pacificação", houve muitos voluntários a se alistarem nas unidades falangistas, colaborando a seguir nas tarefas de "limpeza e punição sob as ordens das autoridades competentes" com a ajuda do contributo económico ( 5 ptas/dia) que recebiam as milícias de falange e cívicos.

13 Fundo A. L. G., p. 18. HISTORGA. 
De referir que ao nível local, mais evidente, mas nem só, também as milícias e a Guardia Civil organizaram muitos dos grupos repressivos. ${ }^{14}$ Principalmente no contexto rural, o papel da Guardia Civil virou decisivo para a organização da estrutura e controlo das milícias, que recebem muitas delegações da função de ordem pública, conquanto se mantivessem sempre sob a autoridade militar. ${ }^{15}$ Assim, as milícias atuam, mormente, a pedido do comandante do posto e logo depois de uma denúncia ter sido apresentada, ${ }^{16}$ por ele próprio, ${ }^{17}$ por um vizinho, pelo pároco, ${ }^{18}$ por um cacique, pelo que bastava o conhecimento pessoal ou algum relatório de uma atuação passada "suspeitosa" da vítima para encenar um motivo para empreender uma ação repressiva. ${ }^{19}$ Isso chegou até ao ponto de se criar um espaço de luta de poder nesse terreno, por exemplo, com a volta do importante poder que tinha a Igreja nas delações, na emissão de certificados de boa conduta, etc.

14 Mesmo, nalguns casos, o delegado militar no Concelho e o comandante do posto da Guardia Civil resultavam ser a mesma pessoa e, por vezes, coincidia que era também o alcaide (em Pontevedra, o chefe da comandância da Guardia Civil, o tenente-coronel Macarrón Piudo, era também delegado de ordem pública). Quanto ao grau de colaboração, torna-se um bom exemplo o caso de Pontevedra, onde o referido chefe da Guardia Cívica, Lis Quibén, instala o posto da mesma no quartel da Guardia Civil, sob o comando do comandante Velarde.

15 Ainda que, nalguns casos, discutiam por volta das "tarefas e respetivas influências", especialmente em espaços de visibilidade nos lugares e aldeias (Fundo 2247 A. G. S. Proxecto Interuniversitario "Nomes e Voces").

16 Uma prova do sucesso em que virou este sistema de denúncias que abrangia "gente suspeita de colaborar", no âmbito do novo rol de poder que estava a ser implementado, diz respeito aos inúmeros avisos na imprensa da época em que se pedia para não serem apresentadas mais denúncias, porque não poderiam ser atendidas aquelas que não satisfizessem, pelo menos, o requisito da assinatura (Faro de Vigo, 06/08/1936).

17 Francisco González Rodríguez, o "Rabioso", falangista e membro da Guardia Civil (Vigo), foi procurar por uma denúncia ao exportador de peixe Aureliano Jaso Almunia, "el Boceras", que tinha essa alcunha porque "era o que mais gritava 'assassinos' e 'mataram a meus irmãos' nas procissões (procissões solenes religiosas ou da Falange)”. Testemunho de uma sobrinha da vítima (Fundo 2124 R. J. R. Proxecto Interuniversitario "Nomes e Voces").

18 O pároco de Bueu (Pontevedra) era conhecido como o "Poderoso" pelas delações de gente de Beluso que vivia fora (Fondo 2313 Colectiva de Bueu. Proxecto Interuniversitario "Nomes e Voces"). Em Cangas do Morrazo (Pontevedra), afirma uma entrevistada que o pároco delatava "aos que abriram a Casa del Pueblo 'porque temos que colaborar', assegurava, e também mandava matar aos de outras paróquias...” (Fondo 2188 D. R. B. Proxecto Interuniversitario "Nomes e Voces").

19 Sob a direção de Víctor Lis Quibén ficou organizado um grupo numeroso composto por guardas civis, guardas cívicos e falangistas que se encarregavam de buscar a pessoas escondidas, trás as denúncias que recebiam, pelas comarcas de Pontevedra, para assassiná-las. Maltratavam ainda aos familiares que tinham pessoas escondidas com vista a conseguirem qualquer informação (Fundo 2108 C. V. M. Proxecto Interuniversitario "Nomes e Voces"). 
Contudo, essas milícias nem sempre atuavam sob ordens. Tais situações são percebidas, sobretudo, em contextos locais e, especialmente no espaço rural, graças a uma margem de manobra mais ampla que tinham os sujeitos, ao que se acrescentavam outros elementos mais complicados de contrastar. Encontramos casos que descrevem as vítimas de atuações "autónomas" das milícias dentro de uma repressão "não controlada". ${ }^{20}$ Encontramos vários repressores que acodem à casa da sua vítima ou ao centro ou local onde esteja detida, movidos por múltiplas e cruzadas motivações e interesses e sem ordens superiores formais ou intervenção direta. ${ }^{21}$ Esses episódios poderiam ser enquadrados no âmbito de uma repressão mais incontrolada das diretrizes da repressão onde, principalmente, antigos confrontos, represálias, invejas e $\operatorname{conflitos}^{22}$ contam aqui com linhas de continuidade, sobretudo nos primeiros meses, sob um clima de "confusão", e onde as atuações à margem da cadeia de repressão foram mais frequentemente "disfarçadas" como "políticas" e foram realizadas sem medo a sanções. ${ }^{23}$

Nesse tipo de atuações, as fontes orais revelam-nos que se destacavam os jovens falangistas e os "que se tornaram de FE para salvar a pele", ${ }^{24}$ que tentavam aproveitar a ocasião de modo a combater a "revolução" e o virus

20 Mais uma vez, o nome do organizador da Guardia Cívica de Pontevedra, Víctor Lis Quibén surge como um dos principais protagonistas de muitos dos episódios mais sangrentos que já foram retidos na memória das comarcas ao redor. Um dos entrevistados afirma que "o grupo armado que tinha às suas ordens [Lis Quibén] desdobrava uma repressão mais violenta do que os da FE” (Fondo 2074 A. C. C. Proxecto Interuniversitario "Nomes e Voces"). Também nos contextos rurais da comarca de Vigo foram recolhidos episódios de guardas (Fondo 2172 J. C. F. Proxecto Interuniversitario "Nomes e Voces") ou os inúmeros episódios de "violência desmedida" que o famoso "Porteiro" de Ourense veio a protagonizar (Fundo O. M. HISTORGA).

21 Algumas das sacas iniciavam-se sob o ofício de ordem de translado ou liberdade. Dessas práticas, para além da cadeia de comando poderiam ser apontados certos indícios nas fontes documentais: ofícios desde os governos civis e militares às prisóes proibindo de tirar os presos para fora sem a respetiva ordem da autoridade. Exemplos dessas situações foram investigados por Suárez (2002) para Ferrol (A Coruña) ou Rodriguez Teijeiro $(2010,2011)$ para Celanova (Ourense).

22 São inúmeros os relatos das vítimas em que são assinalados algum desses aspetos nas motivações, entre os mais destacados, de rivalidades profissionais (Fundo 2074 A. C. C. e Fundo 2137 B. O. M. Proxecto Interuniversitario "Nomes e Voces").

23 É assim que o confessa um antigo militante de FE de Ourense, a respeito de serem sempre atribuídos à $\mathrm{FE}$ os episódios de assassinatos. A fala deste antigo falangista, num comício em Oleiros (A Coruña) onde se acusava à Guardia Civil de encomendar aos falangistas fazerem essas "tarefas", aponta para a importância do elemento pessoal nas aldeias (Fundo A. L. G., p. 21-22. HISTORGA).

24 Nos contextos rurais, a maioria das vezes, esses repressores costumavam ser da mesma aldeia e os entrevistados qualificavam-nos como sendo "gente sem cultura" e que se faziam chamar de "os fasvistas" (Fundo 2247 A. G. S. Projeto Interuniversitario "Nomes e Voces"). 
rojo em qualquer uma das formas em que se pudesse concretizar, como uma espécie de ação defensiva contra o "inimigo". Igualmente, "acompanhavam" esses episódios milicianos de "menor categoria”, sem qualquer ligação às linhas de poder anterior, sujeitos que mormente as fontes orais qualificam de "malfeitores", que antes da guerra eram já conhecidos por atuações ou delitos menores à margem da justiça e que "passaram de roubar a matar". ${ }^{25}$ As fontes também nos assinalam os festejos e comemorações ${ }^{26} \operatorname{logo}$ a seguir aos assassinatos ou quando chegavam notícias com esse teor, bem como o gabar-se destes atos publicamente. ${ }^{27}$ Achamos que esses episódios não se produziram na sequência de uma fratura na cadeia de comando mas como resultado de uma interessada atitude de "olhar para o outro lado", de certa abstenção das responsabilidades no que respeita à "administração da repressão", que, por sua vez, foi sinistramente utilizada e muito eficaz no âmbito da estratégia do terror. No entanto, a autoridade e a estrutura militar podiam usufruir, por mais que frequentemente os tivessem negligenciado, dos mecanismos para controlar e entravar atos descontrolados das milícias; atuavam sim se era contra os seus interesses que se atentava, sobretudo nesses contextos locais que foi onde se registou a maior parte desses episódios violentos.

$\mathrm{Na}$ comarca do Morrazo (Pontevedra) são muitos os episódios desse tipo de repressões. Colocando a atenção nos sujeitos, para o caso do povo de Bueu, os testemunhos coincidem em apontar para a Guardia Civil como organizadora das detenções, em função muitas vezes de listas, e de levar os detidos em grupos numerosos para serem interrogados no Concelho ou no centro de detenção, local onde eram frequentes as surras, bem como as rapas

25 Qualificativos que coincidem com a maioria dos utilizados pelos entrevistados quando se referem a esses grupos de pessoas protagonistas dessa violência descontrolada (entre outros, Fundo 2247 A. G. S. e Fundo 2124 R. J. R. Proxecto Interuniversitario "Nomes e Voces").

26 Um dos conhecidos no âmbito da repressão como o "Faimal" ("faz mal”) apresentar-se-ia depois na casa da entrevistada para lhe dizer que ele não tinha assassinado ao seu irmão, "que o tinham convidado à 'festa' mas que ele recusou-se a assistir". O seu irmão E. J. G. foi assassinado em agosto de 1936 e o seu pai executado em Tui (Pontevedra) como também a sua outra irmã e cunhado (Fundo 2124 R. J. M. Proxecto Interuniversitario "Nomes e Voces").

27 Quanto ao grupo de guardas cívicos que atuavam no rural da comarca de Vigo, é a fonte oral que nos afirma que o chefe "de uma maneira altaneira contava as aventuras que faziam", apresentando-se mesmo na casa de uma das vítimas à hora do almoço (Fundo 2172 J. C. F. Proxecto Interuniversitario "Nomes e Voces"). O famoso "Porteiro" em Ourense, conforme o testemunho próximo de um antigo militante da FE de Ourense, apregoava pelos bares: "Eu abati 17, eu abati 6, 6, 7..." (Fundo O. M., p. 14. HISTORGA). 
de cabelo às mulheres. ${ }^{28}$ Note-se, ainda, a boa relação que a Guardia Civil mantinha com as milícias mas, especialmente, com os falangistas, muitos deles recém-chegados. Segundo os testemunhos, "muitos viraram falangistas e cívicos logo a seguir ao golpe e outros dos que tinham dado surras no Concelho aderiram depois pelo medo aos falangistas e cívicos." ${ }^{29}$ Uma situação comum nos concelhos dessa comarca diz respeito ao grande poder e visibilidade que os falangistas das famílias mais destacadas tinham, bem como os similares procedimentos repressivos e sujeitos colaboradores utilizados. No caso de Bueu, a conhecida família Massó ${ }^{0}$ tornou-se uma das mais visíveis devido aos atos e meios postos ao serviço da repressão, ${ }^{31}$ Assim, as fontes falam de quem se "aproximou" às pessoas mais visíveis e conhecidas do povo nesses atos e ajudam-nos a conhecer algumas das pistas relativamente às motivações de uns e outros. ${ }^{32}$

Os sucessos de repressão paralegal que continuam a se espalhar para a Ria de Vigo também contam com sujeitos próprios, consoante as fontes orais. Um dos factos repressivos mais destacados teve lugar perto de Redondela, sob a direção do chefe da Guardia Cívica em Pontevedra, Víctor Lis Quibén, dirigia um grupo muito numeroso de guardas civis, guardas cívicos e falangistas encarregados de assassinarem as pessoas que se encontravam escondidas trás o golpe ${ }^{33}$ Foi assim que protagonizaram muitos sucessos. Mas, também em Redondela, muitos dos sucessos repressivos tinham a ver com os grupos falangistas locais. Entre os que as testemunhas assinalam como cabecillas

28 Esses atos "exemplificadores" são utilizados nas comarcas costeiras sobre tripulações completas, que figuram em listagens de pessoas que terminam por passar por esses "depoimentos" e surras, mormente, devido à sua atividade sindical (Sindicato de Marinheiros). Coincidem ainda outras fontes orais na hora de apontarem para o facto de as detenções serem efetuadas no Concelho e que era ali que a Guardia Civil “interrogava os detidos para a seguir 'passeá-los' e assassiná-los, também sendo ali as rapas às mulheres republicanas ou das que trabalhavam na indústria de conservas" ( Fundo 2292 e 2313 Colectivas de Bueu. Proxecto Interuniversitario "Nomes e Voces").

29 Também devido a confrontos e medo a represálias, como refere ainda um deles que indica como "para que não ma 'pagassem', tive de me tornar falangista" (Fundo $2301 \mathrm{~J}$. G. Proxecto Interuniversitario "Nomes e Voces").

30 Com seis membros na Falange, cinco empresários ( J. María Massó García chega a ser alcaide franquista, no âmbito das adaptações ao poder trás o golpe) e um médico.

31 Fundo $2301 \mathrm{~J}$. G. Proxecto Interuniversitario "Nomes e Voces".

32 Fundo 2313 Colectiva de Bueu. Proxecto Interuniversitario "Nomes e Voces".

33 Ver uma trajetória dessa personagem em G. Amoedo (2010, p. 255 e ss.). 
estavam famílias de comerciantes de Redondela, da Falange Española, e outros dentro dos falangistas que ordenavam matar. Mesmo alguns protagonizaram situações exemplificadoras, como rapas de cabelo a filhos de mestres, sendo que todos pertenciam à mesma aldeia. ${ }^{34}$

Nas redes de colaboração, segundo as fontes orais, as mulheres dos franquistas de Ponteareas (perto de Vigo) tiveram uma participação destacada, pelo menos mais visível, nem só sob o contexto mais duro das repressões paralegais (com delações), mas também no que diz respeito à configuração do novo regime através dos serviços da Sección Femenina. Elas tiraram, largamente, proveito das tarefas do Serviço Social para assentar uma repressão económica e social em face das mulheres e das famílias das vítimas, vítimas que continuarão a sê-lo no longo pós-guerra. ${ }^{35}$ Quanto aos elos de ligação dos grupos repressivos trabalhados, consoante os testemunhos das fontes, refletem relações nem só dentro de distintos concelhos da mesma comarca, mas entre comarcas distintas da mesma província. Isso torna aparente, uma vez analisados os casos, que os dados mais numerosos de que dispomos sobre esses sujeitos são recolhidos para o caso de Pontevedra. ${ }^{36}$

Nas três comarcas da marinha luguesa, as fontes consultadas revelam-nos uns sujeitos e grupos repressores com uma estrutura similar às que foram analisadas para o contexto da retaguarda. São as famílias dos líderes locais nas vilas, alguns com um certo grau de convicção ideológica, que ordenam os paseos e provocam um clima de medo e tensão contra os potenciais desafetos. Essas famílias dos líderes serão também alvo de outros sujeitos colaboradores na busca de alguma proteção perante o clima de delações na retaguarda. As "tarefas" de limpeza da retaguarda ser-lhes-ão ainda compensadas no futuro com postos na construção do jovem regime franquista, alcaides, vereadores (ainda com linhas de continuidade atualmente). ${ }^{37}$ Mas as fontes nem só mencionam as famílias, mas também a importante colaboração da Guardia Civil

34 Fundo 2108 C. V. M. Proxecto Interuniversitario "Nomes e Voces".

35 Fundo 2112 B. M. P. Proxecto Interuniversitario "Nomes e Voces".

36 Fundo 2013 S. D. R. e Fundo 2137 B. O. M. Proxecto Interuniversitario "Nomes e Voces".

37 Alguma das fontes aponta para as continuidades de alguns membros dessas famílias com a linha do atual PP (Fundo anónimo [por pedido da fonte]. Proxecto Interuniversitario "Nomes e Voces"). 
no que toca aos atos repressivos, vinganças ou ordens dadas a outros colaboradores "inferiores" ${ }^{38}$ As fontes assinalam ainda translados, numerosos, que faziam mesmo ao cárcere de Lugo e inclusive os presos que chegam por mar ao campo de concentração. É preciso lembrar que os presos asturianos capturados em alto mar chegavam a Ribadeo e daí partiam para Ferrol e A Coruña (logo de em Cedeira e Muros serem classificados) ou para Camposancos (trás a respetiva classificação, eram transferidos para um batalhão de trabalho ou enviados para um Conselho de Guerra, a partir de 1938). ${ }^{39}$

Nos contextos rurais das comarcas centrais de Lugo, as agrupações, procedimentos e atuações dos grupos repressivos não diferiam muito do que já foi exposto. $\mathrm{Na}$ área de Castroverde, na comarca de Lugo, muitas das vítimas da repressão provinham da paróquia de Montecubeiro. As fontes insistem na supremacia da Guardia Civil nas operações e detenções e a colaboração de grupos falangistas de Castroverde como instigadores, e de Montecubeiro como executores, em presença do pároco com o fato falangista, mas sempre "sob ordens militares". Destacam, ainda, as operações de busca de foragidos e as "colaborações" de falangistas e párocos e, no nível psicológico ou social, das mulheres dos falangistas. Ao contrário de outras áreas em que os grupos de sujeitos repressores ganham força à volta das famílias mais destacadas, nesse município os repressores dispõem da intervenção da Guardia Civil e dos falangistas chamados de camisas viejas, bem como de jovens, com alguma relevância individual e com a participação muito ativa dos párocos e inclusive rivalidades entre falangistas. ${ }^{40}$

Quanto à cadeia de comando, nas comarcas dessa província galega não se verifica como muito alterada. Guardia Civil, falangistas e párocos atuam sincronizados e com muita disciplina, mesmo nos "procedimentos" dos seus episódios repressores, nenhum com conselho de guerra. Já tínhamos alertado para a importância na busca de foragidos, com especial relevância

38 Fundo 2005 J. D. P. e Fundo 2009 P. C. R. Proxecto Interuniversitario "Nomes e Voces".

39 As penas de cárcere eram cumpridas em Figueirido ou em Celanova enquanto as de morte em S. Simón (Pontevedra), A Guarda (Pontevedra), San Francisco (Ourense), Pontevedra ou Vigo. O de Ribadeo (Lugo) foi criado logo de a ocupação das Astúrias ter finalizado e a começos de 1939 quando da Catalunha chegarão muitos prisioneiros e têm de se pôr novamente em funcionamento algum dos que estavam fechados. Para mais detalhes, ver. D. Rodríguez (2010, p. 123 e ss.).

40 Fundo 2063 M. S. L. Proxecto Interuniversitario "Nomes e Voces". 
nessa província montanhosa e limítrofe, mesmo desenvolvendo procedimentos "alternativos" quando fracassavam essas detenções: falangistas e párocos colaboravam na elaboração de "listagens exemplares" perante os fracassos das detenções, um tipo de pessoas "alternativas" nas que surgiam sempre vítimas por motivos de rivalidades económicas, invejas ou conflitos de períodos anteriores. ${ }^{41}$

Nas comarcas da província de Ourense deparamo-nos mais uma vez com a supremacia das famílias falangistas no respeitante à configuração dos grupos de sujeitos repressores. Na comarca de Valdeorras, as fontes identificam com clareza a duas famílias falangistas no Barco, entre as mais destacadas da comarca (as chamadas "Casas de..."), que detêm uma liderança importante nos episódios repressivos, mesmo com cárceres nas suas casas. $\mathrm{O}$ quartel da Guardia Civil do Barco de Valdeorras não se amostra tão ativo quanto o da Rúa de Petín, mais ainda desde o translado do seu tenente. Quem lidera a campanha dos fugitivos e episódios repressivos no quartel da Rúa são duas famílias falangistas que se destacam em funções como ordenar os atos repressivos através dos seus "criados". Nos casos trabalhados, eram outros que realizavam diretamente os assassinatos ou outro tipo de repressões. Nesta última localidade, as fontes apontam ainda para o ativo papel que desempenharam as mulheres falangistas nesses processos, desenvolvendo-se assim toda uma rede familiar ao serviço da repressão. ${ }^{42}$

Da comarca mais oriental de Ourense para a comarca do Ribeiro Em Ribadavia, segundo a fonte entrevistada, as atuações repressivas focavam-se em detenções de pessoas destacadas do mundo do trabalho e surras, de tipo exemplificador. Os falangistas provinham do vizinho Castrelo de Miño. Os falangistas locais já tinham manifestado a sua presença mesmo antes do golpe, através de manifestações públicas, ainda que fossem uma minoria. ${ }^{43}$

Consoante o testemunho de um antigo militante de FE e das JONS da cidade de Ourense, era tão grande a quantidade de paseos na cidade, que ele

41 Depois de 1939, se destacam cinco mortes da guerrilha, sendo referidos vários sujeitos repressores (governador civil e um comandante) (Fundo 2063 M. S. L. Proxecto Interuniversitario "Nomes e Voces").

42 Fundo 2109 A. P. G. e Fundo 2307 A. L. C. Proxecto Interuniversitario "Nomes e Voces".

43 Fundo 2044 J. B. F. e Fundo 2049 N. A. M. Proxecto Interuniversitario “Nomes e Voces”. 
pediu para ir para a linha de frente após um episódio com o "famoso capitão Federico" que o obrigava a participar neles. Assinala como na área de Celanova, no ano 1937, essa prática continuava sem minorar. Justifica os procedimentos como um "golpe de efeito" sob contextos violentos, porém reconhece que se "saiu de controlo". Na sequência do relato de um episódio em Trives (Ourense) no qual tinha participado, torna responsáveis pela direção dos atos aos militares, mas menciona a participação de "oficiosos civis" e de algum que se filia à Falange para saldar alguma vingança pessoal. Menciona ainda ao famoso "Porteiro" (no local de FE) na cidade de Ourense como protagonista daqueles que tipificamos como atos mais "descontrolados" e que costumavam vir acompanhados de altaneiras manifestações públicas dos seus assassinatos. ${ }^{44}$

Até aqui uma sumária descrição das redes, procedimentos e motivações dos sujeitos repressores trás um percurso pelas principais comarcas das províncias galegas. É uma investigação que continua aberta e que completamos, matizamos e voltamos a focar segundo o avançar da análise de novas fontes, com novas perspetivas metodológicas para o estudo dos sujeitos repressores. Sirva isso de avanço às possibilidades que se abrem a partir dessa investigação. Avançamos com umas primeiras conclusões provisórias, fruto dessa primeira aproximação das fontes da repressão franquista na Galiza.

\section{Algumas conclusões provisórias}

Nessa primeira aproximação da análise das causas e sujeitos da perseguição e repressões na guerra e a ditadura na Galiza, tencionamos não apenas explorar a estrutura repressiva, incluindo a sua atuação e vítimas, mas debruçarmo-nos sobre as suas finalidades, motivações e sujeitos repressores responsáveis por tais atuações. Nesse caminho, deparamos com questões já abordadas e outras mais novas que nos encorajam a continuarmos com a nossa investigação por caminhos que achamos mais adequados e que nos ajudarão a melhor explicar a complexa urdidura tecida nos anos 1930 na Galiza, Espanha e Europa.

44 Fundo O. M. Antigo militante FE e das JONS. Ourense, p. 13-14. HISTORGA. 
Comecemos por apontar para o que ainda temos na coluna de "deve". Uma das primeiras perguntas que nos tínhamos feito e que nos irá acompanhar mesmo até ao fim da investigação é: qual a razão para os carrascos terem ficado sem ser investigados até ao momento? Uma primeira explicação coloca-nos no contexto de uma ditadura e o condicionalismo expresso pela repressão, a censura e a historiografia do regime, mas é também naquela altura que se encetam as tentativas por trazer para o primeiro plano as responsabilidades dos carrascos no devir histórico (os três supostos autores de Galicia mártir incluem epígrafes como "Así era cómo asesinaban"); e foi com o devir historiográfico que se iniciou o estudo das vítimas, depois a justiça... e é esta que colocou, definitivamente, o foco nos carrascos para a história... mas sempre tinham estado lá fora: na memória das vítimas, e nas fontes. Havia apenas que alterar as perguntas para começar a obter outras respostas É assim que de modo a nos aproximar dos sujeitos que protagonizaram as perseguições e eliminações, nesta primeira parte do estudo, focamo-nos nas fontes primárias orais das vítimas e de alguns dos protagonistas falangistas. Temos no horizonte próximo a análise das causas militares que processaram algumas das vítimas que trabalhamos para tentar analisar os relatórios e denúncias que incluem as pessoas que as promovem e os motivos alegados. Além disso, realizaremos o contraste com outras fontes documentais das organizações às quais pertenciam boa parte dos repressores (como os arquivos da Falange e Guardia Civil, etc.), e outro tipo de fontes desse tipo, consoante expusemos na metodologia. Sabemos, contudo, que a pergunta de por que é que os carrascos não foram investigados... virará numa das questóes de fundo conforme o avançar da investigação.

A coluna de "haver" teceu uma poderosa linha logo de examinada a estrutura repressiva: a finalidade política do terror para a conquista do poder e a destruição da cidadania. É nessa linha que se provou eficaz para entender a violência política e a construção da retaguarda enquanto os dois lados da mesma moeda. As motivações e razões subjetivas que nos fornecem as fontes orais trabalhadas (vítimas e falangistas) precisam ser completadas e contrastadas com as fontes das seguintes fases do trabalho, para começar a conhecer as (i)lógicas desse massacre. Foi na sequência do golpe e na guerra que a jovem democracia ficou quebrada e na retaguarda "pacificada" galega (com as violências políticas, perseguições e eliminações radicais dos símbolos do poder democrático, da cidadania e dos princípios liberais) os novos poderes do "Estado Novo" começaram a "readaptar" o sistema consoante a sua 
ordem... perante "o caos", criando assim um jovem regime sob a jovem forma "soberana" de exercer o monopólio da violência, de organizar o Estado e a sociedade, segundo os modelos fascistas contemporâneos do entreguerras.

Nesse sentido, alertamos ainda para a necessidade de continuar a investigar as linhas de continuidade em face das retaguardas, o novo regime e a estrutura sobre a qual irá assentando. Observamos ainda como através dessas linhas de continuidade/ruptura podemos deparar com algumas explicações que digam respeito às motivações e às razões das perseguições e eliminações, tanto no âmbito do contexto democrático como no franquista, sem esqueceremos que ainda temos de encontrar as possíveis engrenagens do "holocausto espanhol" além da diacronia nacional ou galegas e melhor integrar todas as violências políticas trabalhadas, os seus sujeitos e motivações na sincronia fascista europeia, uma "Espanha contra Espanha” em uma Europa contra Europa. Comprovamos ainda a operatividade da análise dos contextos do poder local, da mudança social das elites de forma a explicar e compreender algumas das lógicas surgidas sob o contexto republicano galego. Achamos que continuará a ser demonstrada a operatividade de analisar esses contextos, essa metodologia, permitir-nos-á, por fim, realizar análises comparativas e globais, para o que se torna necessário partir de realidades muito concretas, pois estas são, como diz Conxita Mir (2000, p. 18), "as únicas que permitem compreender as relaçóes interpessoais que explicaram os comportamentos sociais articulados à volta das práticas repressivas do pós-guerra”. Aqui temos que explorar as repressões económicas, sociais, psicológicas, depurações... que marcaram o pós-guerra.

E ligado com isto... outras das primeiras perguntas: quais as razões para terem matado? E a quem? Nesta primeira fase da investigação contamos com alguma conclusão provisória no que diz respeito ao caso galego, consoante os casos locais estudados: no denominador comum deparamos, em maior ou menor medida, com as motivações pessoais. É a história da memória das vítimas, mas nem só; temos ainda o testemunho de falangistas a referirem, de maneira secundária ou principal, os motivos pessoais (vinganças, invejas, inimizades passadas); o elemento do terror, de "alastrar o terror" que vimos para os mais terríveis assassinatos, a visibilidade do medo no controlo de uma retaguarda potencialmente perigosa... Estavam presentes também as razões militares, certamente, a conquista do poder pelas armas, de modo a garantir uma retaguarda pacífica e que, ao mesmo tempo, abastecesse para a guerra; e... sempre, em todos os casos, e com matizes adaptativos... as motivações da 
luta pelo poder: poder político, poder militar, poder social, poder económico e poder social. Não lhes serviam as vias democráticas, as da cidadania... mas eram essas que queriam destruir. É assim que a construção da ditadura, através de postos na administração, etc., alicerçou-se também na participação dos repressores na "limpeza" da retaguarda, destruindo e construindo uma retaguarda política, social e económica nova, longe das vias do Estado de direito e através das repressões como ação política, isto é, a finalidade política do terror com vista a ter o poder e destruir a cidadania. Nesse ambiente, a memória das testemunhas surge muito forte e oferece-nos o relato do poder das violências nos novos atores sociais. Daí o ecoar de frases inesquecíveis como "novos ordenantes da sociedade, aos falangistas, estorvava-lhes muita gente, e foram trás deles"... "o pai foi a perguntar-lhe ao pároco por que é que assassinaram o filho" e o cura respondeu: "Nós temos é que impor o terror!" (Cura Q., A Cañiza. Pontevedra); “... os caciques do povo queriam continuar a ser os donos do povo [...] não queriam ver os pobres a ler nem escrever...” (A. M., Professor). ${ }^{45}$

Temos vindo a comprovar, tal como nos foi revelado até ao momento pelas fontes analisadas, como a repressão não assentou apenas na disciplina e hierarquia castrense, "nas ordens militares", mas também de forma muito importante na Falange, para canalizar essa violência política, e ainda permitir a absolvição sob a "política" a todos aqueles que protagonizaram os episódios mais descontrolados de perseguições e eliminações. Nos episódios avaliados pudemos verificar como a Guardia Civil (enquanto instituição, não nos casos de protagonistas individuais) em muitos dos sucessos repressivos surge relegada para um lugar secundário, colaborador ou não delator, sendo que as milícias aparecem como executoras diretas, juntamente com muitas motivações, ficando presentes sempre as pessoais, e mesmo com protagonistas muito violentos, segundo relatam as memórias das vítimas. Temos de aprofundar nas conformações e motivações que desembocaram nas ações violentas dessas famílias destacadas de falangistas no âmbito local, o que faziam antes do golpe, qual a sua ocupação, etc. e ir perspetivando uma nomenclatura mais apropriada do que a de "boas famílias", talvez "falangistas de liderança familiar" ou uma categoria mais adequada nesse sentido. Ainda, pelo

45 Fundo 2011 T. C. P. Proxecto Interuniversitario "Nomes e Voces"; Cura Quiroga, A Cañiza (Pontevedra) e A. M. V. (professor, encarcerado em Vigo [em cartas perdoa aos carrascos] e assassinado no Castro e enterrado em Pereiró (Fundo 2068 J. M. V. Proxecto Interuniversitario “Nomes e Voces"). 
que pudemos verificar, no que toca aos sujeitos individuais, protagonistas de ações "descontroladas" desde a direção de guardas cívicos, Guardia Civil ou FE, precisam ser estudados também os seus antecedentes, analisar a sua origem, filiações, relações com outros grupos, o seu papel na repressão judicializada... e tentar, assim, obter informações relativamente às motivações para as perseguições e eliminações de pessoas. Ainda, outro dos tipos de sujeitos repressores costumam ser colaboradores, delatores... costumavam partilhar um perfil, consoante às fontes orais, de pessoas com uma vida prévia quase à margem da legalidade, "gatunos, ladrãozinhos”... era assim que os qualificavam, e que "aproveitavam" para aderir a essas violências, perseguições e eliminações mais fortes dos primeiros meses. As fontes referem ainda, nessa cadeia repressiva, aos delatores, aos que denunciam, às mulheres falangistas, aos párocos (também em qualquer caso enquanto executores diretos), que a sua simpatia unia-os à proteção da nova ordem e cujos atos iniciáticos inseria-os "passivamente" na cadeia de repressão.

$\mathrm{Na}$ linha da conceptualização apontada e logo de termos examinado os casos nos contextos micro, observamos como a operatividade da mesma terminologia da tipologia da "repressão" não termina por se ajustar aos exemplos trabalhados. Conquanto apreendamos a tipologia que para o estudo da repressão propõe J. Prada (2003) temos observado, uma vez que analisada a estrutura repressiva nos níveis locais e comarcais, que alguns conceitos ou tipologias poderiam bem ser revistos, a começar pelo próprio conceito de repressão; relativamente a isso, achamos mais pertinente e mais ainda conforme a investigação avança, mesmo do ponto de vista teórico, falarmos em "violência(s) política(s)". O mesmo pensamos em relação à própria funcionalidade da tipologia utilizada nesta primeira fase, "repressão paralegal” e que, à medida que aprofundamos os estudos de caso, talvez alguma categoria como "violência política não institucional” ou "perseguição não institucional" poderia ajustar-se mais e provar um maior grau de precisão e operatividade. Estes são aspetos nos que estamos a trabalhar e que irão sendo perfilados com o avançar da nossa investigação. 


\section{Anexo I}

Fundo fontes orais. Proxeto Interuniversitario "Nomes e Voces"

Consulta indexação completa

Consulta seleção categorias

<Repressão-repressores >

Antes 1936 | Golpe | Guerra

Depois de 1939

$<$ Falange e direitas antirregime $>$

Antes 1936 | Golpe | Guerra

Depois de 1939

$<$ lgreja $>$

Antes 1936 | Golpe | Guerra

Depois de 1939

Cruzado categorias

$<$ Repressão-repressores $>$

$<$ Falange e direitas antirregime $>$

$<$ lgreja $>$

[não apenas referência das vítimas familiares diretas, mas outros próximos ou reconhecidos]

$\mathrm{N}^{\circ}$ minutos categorias selecionadas

Assessoramento grupo investigador projeto
472 entrevistas

contém categoria

203 entrevistas

63 entrevistas

141 entrevistas

48 entrevistas

48 entrevistas

18 entrevistas

resultado coincidentes $>$ seleção amostra

33 entrevistas 


\begin{tabular}{|c|c|c|c|c|}
\hline \multicolumn{5}{|c|}{ Amostra selecionada 33 entrevistas } \\
\hline \multicolumn{5}{|l|}{$\mathrm{n}^{\circ}$ entrevistas } \\
\hline província & total & contexto capital & vilas e & $\begin{array}{l}\text { local } \\
\text { iencionadas }\end{array}$ \\
\hline A Coruña & 1 & 0 & 1 & Sada \\
\hline Lugo & 6 & 0 & 6 & $\begin{array}{l}\text { Castroverde } \\
\text { Monforte } \\
\text { Montecubeiro } \\
\text { Piñeira } \\
\text { Pobra de } \\
\text { Brollón } \\
\text { Ribadeo }\end{array}$ \\
\hline Ourense & 4 & 1 & 3 & $\begin{array}{l}\text { Arnoia } \\
\text { O Barco } \\
\text { Oliveira } \\
\text { Ribadavia } \\
\text { A Rúa }\end{array}$ \\
\hline Pontevedra & 22 & 7 & 15 & $\begin{array}{l}\text { A Cañiza } \\
\text { Alcabre } \\
\text { Bouzas } \\
\text { Bueu } \\
\text { Cabral } \\
\text { Cangas } \\
\text { Lavadores } \\
\text { Mazaricos } \\
\text { Ponteareas } \\
\text { Portonovo } \\
\text { Redondela } \\
\text { Tui } \\
\text { Vilagarcía }\end{array}$ \\
\hline
\end{tabular}




\section{Referências}

AMOEDO, G. A memoria e o esquecemento: o franquismo da provincia de Pontevedra. Vigo: Edicións Xerais de Galicia, 2010.

ARÓSTEGUI, J. (Ed.). Ayer: Dossier Violencia y política en España, n. 13, 1994.

BRENAN, G. The Spanish labyrinth: an account of the social and political background of the Civil War. Cambridge: Cambridge University Press, 1985.

CASANOVA, J. (Coord.). El pasado oculto: fascismo y violencia en Aragón (1936-1939). Madrid: Siglo XXI, 1992.

. (Coord.). Morir, matar, sobrevivir: la violencia en la dictadura de Franco. Barcelona:

Crítica, 2002.

CONSTENLA, T. España masacrada. El Pais, 27 mar. 2011. Disponível em: <http://elpais. com/diario/2011/03/27/eps/1301210816_850215. html> Acesso em: 28 mar. 2011.

FERNÁNDEZ, C. Alzamiento y guerra civil en Galicia (1936-1939). Sada (A Coruña): Ediciós do Castro, 2000.

. “As vítimas, os nomes e as voces”. La repressió a Galícia (1936-1939). L’Avenç, n. 335, p. 44-49, 2008.

JACKSON, G. La República española y la guerra civil, 1931-1939. reimp. Barcelona: Crítica, 1995.

. Causas de la guerra de España: Azaña, Manuel, 1880-1940. Barcelona: Crítica, 2002.

MIR, C. Vivir es sobrevivir: justicia, orden y marginación en la Cataluña rural de posguerra. Lleida, Milenio, 2000.

PAYNE, S. G. El colapso de la República: los orígenes de la Guerra Civil (1933-1936). Madrid: La Esfera de los Libros, 2005.

- ¿Por qué no se consolida la Segunda República?. In: BULLÓN DE MENDOZA, A.; TOGORES, L. E. (Coord.). La República y la Guerra Civil: setenta años después. Madrid: Editorial Actas, 2008. p. 15-26.

PRADA, J. Metodoloxía e fontes para o estudo da represión en Galicia. Ourense: Universidade de Vigo, 2003.

PRESTON, P. El holocausto español: odio y exterminio en la Guerra Civil y después. Barcelona: Debate, 2011. 
RODRIGO, J. (Ed.). Ayer: Dossier Retaguardia y cultura de guerra, 1936-1939, n. 76, 2009.

RODRÍGUEZ TEIJEIRO, D. Presos e prisións na Galicia de guerra e posguerra: 1936-1945. Vigo: Galaxia, 2010.

. Las cárceles de Franco: configuración, evolución y función del sistema penitenciario franquista. Madrid: Los Libros de la Catarata, 2011.

SUÁREZ, X. M. Guerra civil e represión en Ferrol e comarca. Ferrol: Concello de Ferrol, 2002.

THOMAS, H. La Guerra Civil española. Barcelona: Grijalbo Mondadori; D. L., 1995.

TUSELL, J. Historia de España. Madrid: Taurus, 2001.

. Dictadura franquista y democracia: 1939-2004. Barcelona: Crítica, 2005.

. Historia de España en el siglo XX. Madrid: Taurus; D. L., 2007.

Resumo: As investigações que dizem respeito à natureza das repressões franquistas continuam a ser a ponta-de-lança da historiografia espanhola sobre a guerra civil e a repressão. Este contínuo crescimento não é apenas quantitativo, mas, sobretudo - e é isto que visamos apontar em nosso artigo -, qualitativo, graças ao aprimoramento de novas fontes e à utilização de instrumentos de análise melhorados e de conceitos mais aperfeiçoados. É por isso que na nossa investigação tencionamos uma nova abordagem: uma aproximação às fontes orais e documentais que já tinham sido utilizadas para o estudo das vítimas para abordar o caso dos sujeitos repressores. Graças à metodologia ad hoc que desenvolvemos, podemos obter uma ideia mais ajustada daquilo que tinha sido o aparelho repressivo e, mesmo, de conceitos que surgirão mais funcionais na hora de abordar o estudo dos sujeitos repressores. Propomos explorar as motivações e as lógicas que animaram as práticas repressivas em uma região como a Galiza. Serão buscadas novas possibilidades em fontes diversas, dentre elas, destacamos o importante fundo oral sobre a repressão na Galiza do Proxecto Interuniversitario "Nomes e Voces".

Palavras-chave: memória, história oral, ditaduras e regimes totalitários, repressores.

The use of the oral archive of Proxecto Interuniversitario "Nomes e Voces" [inter-university project "Names and Voices"]. Case study: causes and agents of political persecution and repression during the Spanish civil war and Franco's dictatorship in Galicia (1936-...).

Abstract: Research on the nature of Francoist repression remains at the forefront of Spanish historiography on the civil war and repression. This continuous boom is not only quantitative but above all - and this is what interests us more in our article - qualitative, because of the enhancement of new sources and the employment more refined concepts and improved analysis instruments. There for, we situate our research in a new approach to oral and documentary sources that were already used for the study of the victims and that allows us to study the 
repressive subjects. Thanks to an ad hoc methodology that we have developed, is possible now to get tighter nuances of the repressive framework and, even, of concepts that prove more operational in our case. We intend to explore the possibilities of analysis for the study of the motivations and the logic that encouraged repressive practices in an area such as Galicia. The work relies on the exploration of new possibilities of sources, among them, the important oral archive on repression in Galicia of the Proxecto Interuniversitario "Nomes e Voces".

Keywords: memory, oral history, dictatorships and totalitarian regimes, repressive agents.

Recebido em 01/10/2012

Aprovado em 14/11/2012 